\title{
Review
}

\section{Nitrate reduction and nitrogen fixation in symbiotic association Rhizobium - legumes}

\author{
Robert Luciński ${ }^{凶}$, Władysław Polcyn and Lech Ratajczak \\ Department of Plant Physiology, Adam Mickiewicz University, Niepodlegtości 14, 61-713 Poznań, \\ Poland
}

Received: 21 November, 2001; revised: 13 February, 2002; accepted: 20 April, 2002

Key words: bacteroids, gas diffusion resistance, dissimilatory nitrate reduction, nitrate reductase (NR), nitrogenase, root nodules

\begin{abstract}
The inhibitory effect of nitrate on nitrogenase activity in root nodules of legume plants has been known for a long time. The major factor inducing changes in nitrogenase activity is the concentration of free oxygen inside nodules. Oxygen availability in the infected zone of nodule is limited, among others, by the gas diffusion resistance in nodule cortex. The presence of nitrate may cause changes in the resistance to $\mathrm{O}_{2}$ diffusion.

The aim of this paper is to review literature data concerning the effect of nitrate on the symbiotic association between rhizobia and legume plants, with special emphasis on nitrogenase activity. Recent advances indicate that symbiotic associations of Rhizobium strains characterized by a high nitrate reductase activity are less susceptible to inhibition by nitrate. A thesis may be put forward that dissimilatory nitrate reduction, catalyzed by bacteroid nitrate reductase, significantly facilitates the symbiotic function of bacteroids.
\end{abstract}

Nitrogen $(\mathrm{N})$ is the major limiting nutrient for most plant species (Greenwood, 1982). Plants require $\mathrm{N}$ from soil or from atmosphere, by symbiotic $\mathrm{N}_{2}$ fixation (Vance, 1990). Soil-derived $N$, generally in the form of
$\mathrm{NO}_{3}{ }^{-}$, is reduced to ammonia by a two-step process. The first step, reduction of nitrate to nitrite, is catalysed by the plant nitrate reductase (EC 1.6.6.4; NR, Solomonson \& Barber, 1990), which is an inducible plant en-

${ }^{\circledR}$ Correspondence to: Robert Luciński: Bukowa 12/4, 61-445 Poznań, Poland; tel: 0607188 788;

e-mail: rtl@main.amu.edu.pl

Abbreviations: $\mathrm{N}$, nitrogen; $\mathrm{NO}_{3}{ }^{-}$, nitrate; NR, nitrate reductase; cNR, constitutive NR;

iNR, inducible NR. 
zyme, depending on the availability of nitrate and light (Campbell, 1999). In regulation of NR activity both, gene expression and post-translational processes are involved (Kaiser \& Huber, 2001), however these aspects will not be considered here. In this paper the relationship between bacteroid nitrate reductase (EC 1.7.99.4.; NR) activity and $\mathrm{N}_{2}$ fixation will be presented.

For a long time it has been well known that nitrate inhibits nitrogenase activity in legume plant nodules. Many investigators have demonstrated the negative effect of nitrate on root infection by Rhizobium, and on the ratio of the nodule dry mass to the whole plant mass. The effect of nitrate on the symbiosis between legumes and rhizobia can be divided into three major areas: (1) the role of nitrate availability during root infection, (2) the relationship between nitrate availability and nitrogenase activity, and (3) the effect of nitrate on the ratio of the nodule dry mass to the whole plant mass (Streeter, 1988).

Aside from nitrogenase activity, in many symbiotic associations between legumes and rhizobia the activity of nitrate reductase has also been observed, e.g. in root nodules of soybean (Heckeman \& Drevon, 1987; Hunter, 1983; Randall et al., 1978) and in yellow lupin. According to our results NR activity in nodules of yellow lupine is a few dozen times higher than in other parts of the plant (Polcyn \& Luciński, 2001). Moreover, 97\% of nodular NR activity is localized in bacteroids (Polcyn \& Luciński, 2001). Taking this into consideration, two hypotheses concerning direct relationship between NR activity and inhibition of nitrogenase have been put forward. The first explains the decrease in the efficiency of $\mathrm{N}_{2}$ fixation as the effect of competition for reductive power between nitrogenase and NR. The second hypothesis proclaims that inhibition of nitrogenase by nitrite is generated by bacteroid NR activity (Riguard, 1976; Streeter, 1988; Becana et al., 1989; Sprent et al., 1987; Giannakis et al., 1988; Becana \& Sprent, 1987; Arrese-Igor et al., 1997).
It is known that the concentration of free oxygen inside nodules is the major factor affecting nitrogenase activity (Layzell \& Hunt, 1990). Oxygen availability in the infected zone of root nodules is controlled by the plant host (Steeter, 1994; Parsons \& Day, 1990; Ianetta et al., 1993; James et al., 1991; Witty et al., 1984; Drevon et al., 1995; Layzell et al., 1990; Minchin, 1997). On one hand, this is due to the presence of leghemoglobin; on the other hand oxygen availability is limited by the diffusion resistance (Streeter, 1994; Parsons \& Day, 1990; Appelby, 1984; Becana \& Klucas, 1992; Robertson et al., 1984; Chamber-Perez et $a l ., 1997)$. The presence of nitrate may directly or indirectly influence the efficiency of gas diffusion resistance (Minchin et al., 1986a; 1986b; Schuller et al., 1988; Vessey et al., 1988a; Caroll et al., 1987; Arrese-Igor et al., 1997).

There are several publications demonstrating that enhancement of $\mathrm{N}_{2}$ fixation is due to the presence of active NR in bacteroids. Symbiotic associations in which NR function is complementary to that of nitrogenase are possible since bacteroids of many rhizobial strains are capable of performing dissimilatory nitrate reduction (Chamber-Perez et al., 1997; Serrano \& Chamber, 1990). The role of denitrification might be dual. On one hand it would remove toxic nitrite, on the other hand it could supply ATP under oxygen deprivation during the first step of denitrification process named nitrate respiration (Fig. 1) (Arrese-Igor et al., 1990; Garcia-Plazaola et al., 1993; Daniel et al., 1982; O'Hara \& Daniel, 1985; Chamber-Perez \& Serrano, 1991).

The data presented above suggest that $\mathrm{N}_{2}$ fixation and denitrification, two processes that are antagonistic in the nitrogen cycle, may perform complementary functions in the cells of symbiotic rhizobia that would be important for survival of bacteria inside root nodules.

In the first part of this paper we would like to present the influence of nitrate on nodule formation, and on the ratio of their mass to the whole plant mass. In the second part, the hy- 
potheses explaining the inhibition of nitrogenase activity by nitrate, both from the plant host's and the microsymbiont's side, will be discussed.

\section{THE INFLUENCE OF NITRATE ON NODULATION}

There is much information on the negative effect of nitrate on the nodulation induced by rhizobia (Champigny et al., 1985; Giannakis et al., 1988; Alcantar-Gonzales et al., 1988). Until the end of the 80 's, it was believed that the presence of nitrate in medium completely inhibited or drastically reduced the efficiency of infection in strains that possessed any NR activity (Alcantar-Gonzales et al., 1988). However, it was shown that at least in some Rhizobium strains the presence of nitrate did not affect this process negatively. Serrano \& Chamber (1990) investigated three Bradyrhizobium sp. (Lupinus) strains differing in NR activity: the first strain possessed constitutive NR (cNR), the second inducible NR (iNR), and the third did not express $\mathrm{NR}$ activity $\left(\mathrm{NR}^{-}\right)$. The results demonstrated that the strains with $\mathrm{cNR}$ and iNR activity were capable of infecting roots sufficiently even at relatively high $(12 \mathrm{mM}) \mathrm{ni}-$ trate concentration, whereas the $\mathrm{NR}^{-}$strain completely lost the ability to form nodules. Moreover, at nitrate concentration of 1-2 $\mathrm{mM}$, the strains with NR activity (either constitutive or inducible) infected roots slightly more efficiently than in the absence of nitrate. The described "patterns" of infection ability resulted in production of durable nodules, which was observed three weeks after. These results show that there is a possibility of formation of symbiotic associations, in which the presence of nitrate does not inhibit nodulation. The effect of NR activity on the efficiency of root infection might be explained by the removal of nitrate ions from the bacterial environment (O'Hara \& Daniel, 1985).

\section{INFLUENCE OF NITRATE ON LOSS IN THE ROOT NODULE DRY MASS}

The majority of legume plants respond to the presence of nitrate in medium by loss in their protein content and nodule dry mass (Arrese-Igor et al., 1990). The presence of active NR, however, may alter the scale of this process. Serrano \& Chamber's (1990) experiments with yellow lupin (Lupinus luteus) infected with three Bradyrhizobium spp. (Lupinus) strains showed that the mass of nodules produced by the strains with NR activity (either inducible or constitutive) was higher than the mass of nodules produced by the NR-negative strain. This effect was positively correlated with the nitrogen content in plant shoots. Other symbiotic associations also show some degree of resistance to nitrate. Root nodules initiated by Rhizobium melilloti are capable of keeping a constant protein concentration in the presence of $5 \mathrm{mM}$ $\mathrm{KNO}_{3}$ (Arrese-Igor et al., 1997). These examples prompted some authors to claim that nitrate alone is unable to upset both the symbiosis itself and its initiation (Serrano \& Chamber, 1990).

Resistance of several Rhizobium species to nitrate during infection and nodulation may, to a certain degree, depend on the activity of hydrogenase, an enzyme characteristic of some diazotrophs. The strains with hydrogenase activity are more tolerant to nitrates (Serrano \& Chamber, 1990). Hydrogenase is a membrane enzyme that contributes to formation of $\mathrm{H}^{+}$gradient across bacteroid membrane, which enables ATP synthesis. In $E$. coli the $\mathrm{H}^{+}$gradient may also be used by the membrane NR for nitrate reduction due to difference in the potentials: $-0.42 \mathrm{~V}$ for hydrogenase and $+0.42 \mathrm{~V}$ for NR (Unden, 1997). 


\section{INFLUENCE OF NITRATE ON NITROGENASE ACTIVITY}

A decrease in the efficiency of nitrogen fixation by bacteroids in the presence of nitrate was repeatedly reported (Chamber-Perez et al., 1997; Serrano \& Chamber, 1990; ArreseIgor et al., 1997; Minchin et al., 1986a; Riguard, 1976). Many hypotheses have been proposed to explain the mechanism of the nitrate effect, yet it still remains unclear. Most of the research concerning this problem approached it from the plant host's "viewpoint", overlooking the fact that the bacterial microsymbiont is not entirely subordinated to plant metabolism. In recent years, several papers were published showing the other side of the symbiotic associations and they reported new observations might be helpful in attempts at understanding the effect of bacteroid nitrate and nitrite reductases on nitrogenase activity. These results will be discussed in the final chapter.

Hypotheses explaining the decreased nitrogen fixation as the effect of decreased bacteroid respiration, caused by increased resistance to $\mathrm{O}_{2}$ diffusion in the nodule cortex, appeared in the 80's (Minchin et al., 1986a; 1986b). The fast changes in gas diffusion resistance have been explained by various mechanism: as changes in osmotic potential of nodule cells (Witty et al., 1986), filling of intercellular spaces in nodules by $\mathrm{H}_{2} \mathrm{O}$ molecules (Witty et al., 1986; Walsh et al., 1989; Ismade, 1991), or variable quantity of passing phloem sap (Layzell \& Hunt, 1990).

There are numerous data confirming the presumption that the presence of nitrate rises the gas diffusion resistance (Fig. 1). In the presence of nitrate, both the energy cost of nitrogen fixation (expressed as the quantity of released $\mathrm{CO}_{2}$ per mol of reduced $\mathrm{C}_{2} \mathrm{H}_{2}$ ) and the gas diffusion resistance increases, but the efficiency of bacteroid respiration (measured as $\mu \mathrm{mol} \mathrm{CO}_{2}$ per gram dry mass per min) decreases.

Some authors have suggested that the increase in gas diffusion resistance could be a secondary response to metabolic changes, as in the case of the effects caused by water stress and low temperature (Arrese-Igor et al., 1997).

\section{INFLUENCE OF NITRATE ON GAS DIFFUSION RESISTANCE}

One of possible ways in which nitrate can affect the gas diffusion resistance is its direct influence (Minchin et al., 1986a; Caroll et al., 1987; Vessey et al., 1988a; Diaz del Castillo \& Layzell, 1995; Kuzma et al., 1995). About 90\% of the nitrate applied onto the nodule surface accumulated in the nodule cortex (Sprent et $a l ., 1987)$. Vessey and Waterer (1992) suggested that high nitrate concentration could cause formation of a local $\mathrm{pH}$ gradient or electrochemical gradient due to differences in the concentration of nitrate or in their reduction rate between cell layers. This was believed to affect gas permeability of cortex cell layer, and consequently to cause conditions in which nitrogenase activity was limited by deficiency of $\mathrm{NAD}(\mathrm{P}) \mathrm{H}_{2}$ and ATP (Minchin et al., 1989; Sprent et al., 1987) (Fig. 1). The intensity of lupin bacteroid respiration corresponded to as much as $83 \%$ of total respiration activity in the infected zone (Ratajczak et al., 1996). In such a situation, lowered bacteroid respiration activity, caused by an increase in the resistance to $\mathrm{O}_{2}$ diffusion, could be the reason of significant ATP deprivation.

The second possibility is the indirect influence of nitrate by limiting supply of carbohydrates into the nodule. It was suggested that the inhibitory effect of nitrate on nitrogenase activity could be caused by decreased supply of carbohydrates to root nodules (Small \& Leonard, 1969). When a large part of the host plant mass is involved in nitrate assimilation, the burden of the demand for reductive power and carbon frameworks is shifted from nodules to other organs. Therefore, intense nitrate metabolism in roots and leaves might lead to decrease a supply of carbohydrates to 


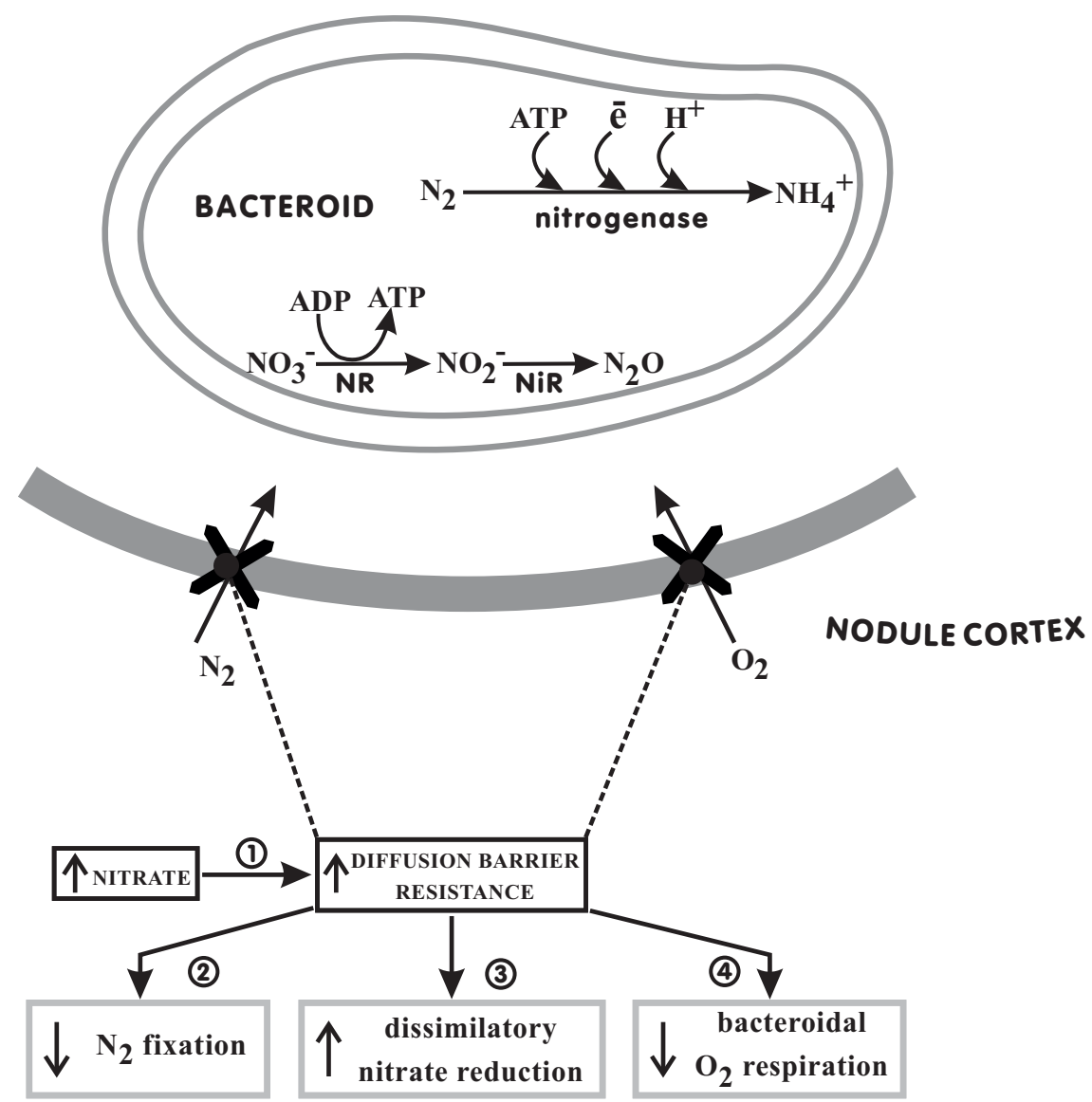

Figure 1. Effect of the gas diffusion barrier in nodule cortex on bacteroid nitrogen fixation and dissimilatory nitrate reduction.

Nitrate directly or indirectly causes the increase of diffusion barrier resistance (1) which then led to decrease of $\mathrm{N}_{2}$ fixation (2) and bacteriodal $\mathrm{O}_{2}$ respiration (4) (Minchin et al., 1989; Sprent et al., 1987; Vessey et al., 1988b; Vessey \& Waterer, 1992) Lowering of nodule oxygen conditions stimulate simultaneously dissimilatory nitrate reduction (3) (Arrese-Igor et al., 1997), NR, NiR, dissimilatory nitrate and nitrite reductases.

nodules (Vessey et al., 1988b). Consequently, it lowers the energy state and increases the resistance to diffusion of gases, including oxygen. Another interpretation suggests that the efflux of carbohydrates from the nodule may decrease their osmotic action towards the diffusion barrier, which would lower its permeability (Vessey et al., 1988b).

\section{PHLOEM TRANSPORT CONCEPTION}

Parsons et al. (1993) explained changes in nitrogenase activity as the result of high concentration of nitrogen containing compounds flowing in with the phloem sap from lower leaves into the surroundings of root nodules, which could inhibit both the nodule growth and nitrogenase activity. Such an effect could be caused indirectly by changes in the resistance to $\mathrm{O}_{2}$ diffusion induced by high concentration of nitrogen compounds containing a reduced form of $\mathrm{N}$ (e.g., some amino acids and amides) in the phloem sap flowing into the nodule surroundings. In the case of legume plants, which nodules export reduced nitrogen as amides, such compounds as glutamate, serine or proline may play an important role.

This hypothesis was supported by experiments indicating increased nitrogenase activity in plants that had only young leaves and decreased level of nitrogen fixation in plants with only old leaves (Malik, 1983). It can be concluded that components originating from leaves, such as compounds containing reduced nitrogen, the concentration of which is 
higher in phloem sap from older leaves, can affect nitrogen fixation.

\section{DENITRIFICATION AS A SYSTEM COMPLEMENTARY TO NITROGENASE}

Aside from nitrogenase activity, high NR activity is characteristic of many symbiotic associations between legumes and rhizobia. In several species, such as pea, bean (Becana \& Sprent, 1987), and vetch (Caba et al., 1995), NR occurs only in nodule cytosol. In other species, e.g., soybean (Hunter, 1983), lucerne (Becana et al., 1985a; 1985b), yellow lupin (Alikulow et al., 1980), and narrow-leaf lupin (Manhart \& Wong, 1980), NR activity has been detected also in bacteroids. Moreover, in soybean (Hunter, 1983) and lucerne (Becana et al., 1985a; 1985b), the activity of bacteroid NR forms $90 \%$ of total nodule NR activity. For this reason, as early as in the 70's, it was believed that the decrease in nitrogenase activity in the presence of nitrate was caused by accumulation of toxic nitrites - products of the NR activity. This, however, would require accumulation of nitrite inside bacteroids, while several researchers have demonstrated that this process is strongly limited (Sprent et al., 1987; Giannakis et al., 1988; Becana et al., 1989).

On the other hand, there are also data that nitrate might have access to the inside of bacteroids (Arrese-Igor, 1990) as a strong induction of nitrate reductase activity by the presence of nitrate was observed in lucerne bacteroids, independently of the type of investigated Rhizobium strain (Arrese-Igor, 1990).

The presence of nitrite reductase activity allows nitrite to accumulate inside bacteroids only for a short time and in low quantity (Becana et al., 1989). This was confirmed by Serrano \& Chamber (1990) and Becana et al. (1985b), who demonstrated that the addition of nitrates caused an increase in NR activity and a simultaneous high increase in nitrite reductase activity in the bacteroid fraction.
Moreover, the activity of nitrite reductase may even surpass NR activity, effectively preventing the accumulation of nitrites inside bacteroids.

When considering the effect of nitrate on nitrogenase activity, one should keep in mind that the presence of nitrate ions does not cause degradation of nitrogenase. The amount of enzyme protein remained at a constant level for 8 days following the addition of nitrate, and it remains so even for the next 20 days (Arrese-Igor et al., 1997). This observation is in agreement with the results of other studies showing that the repression of nitrogenase activity is reversible. Thus, neither the presence of nitrate in medium nor an increase in the resistance to $\mathrm{O}_{2}$ diffusion do cause permanent inhibition of nitrogenase: the inhibition is reversible after removal of nitrate from the medium (Arrese-Igor et al., 1997; Noel et al., 1982).

Legume plants differ considerably in their tolerance to nitrate. Some varieties of soybean are capable of fixing nitrogen despite the presence of relatively high nitrate concentration (Serraj et al., 1992). The activity of nitrogenase in yellow lupin nodules grown in the presence of 3, 5 and $7 \mathrm{mM} \mathrm{NO}_{3}{ }^{-}$for 40 days was higher by $246 \%, 159 \%$ and $133 \%$, respectively than in nodules grown in the absence of $\mathrm{NO}_{3}{ }^{-}$(Lang et al., 1993).

A variety of narrow-leaf lupin was found in which a $40 \%$-stimulation of the nitrogenase activity occurred despite the fact that the plant was grown on a medium containing $15 \mathrm{mM}$ $\mathrm{NO}_{3}{ }^{-}$(Manhart \& Wong, 1980).

These data suggest that after appropriate selection of a legume plant and a nitrate-resistant Rhizobium strain, it is possible to obtain a symbiotic association that is capable of fixing nitrogen despite the presence of nitrate in the medium.

Chamber-Perez et al. (1997) compared the values of several parameters influencing nitrogen fixation (dry and fresh mass, total nitrogen content in shoots, specific and whole nitrogenase activity) with NR activity in 
Bradyrhizobium spp. (Lupinus) strains. The results indicated a high positive correlation between the presence of NR activity and the majority of the parameters related to nitrogen fixation, suggesting that NR activity may play functions complementary to these of nitrogenase (Serrano \& Chamber, 1990). A positive correlation between the nitrogen content in shoots and NR activity is in agreement with the suggestion that NR activity is somehow correlated with the nitrogen metabolism of the whole plant not, however, necessarily in a direct way.

The presence of NR in bacteroids is related to their ability to dissimilatory nitrate reduction. This process can also occur in free-living rhizobia under anaerobic or microaerobic conditions (O’Hara \& Daniel, 1985).

The experiments carried out on soybean nodules demonstrated that the addition of nitrate caused, apart from an increase in the resistance to $\mathrm{O}_{2}$ diffusion, a high increase in the level of denitrification in relation to the control grown without nitrate (Arrese-Igor et al., 1997) (Fig. 1). It should be emphasized that the level of nitrite reductase activity was 10 times higher than NR activity, which guaranteed that nitrite originating in the infection zone was quickly removed.

The ability to denitrify may facilitate survival of free-living rhizobia during temporary hypoxia or anoxia in the soil. It has been demonstrated that bacteroids could utilize ATP originating from nitrate respiration to fix nitrogen (O’Hara \& Daniel, 1985). Such an adaptation would be especially profitable to bacteroids at times of restricted aerobic respiration, caused by, e.g. draught or flooding of the root zone (Serraj et al., 1999). Denitrification may also play a role in detoxification when high activity of the cytosol NR may cause nitrite accumulation (Becana et al., 1985a; 1985b; Heckman \& Drevon, 1987). Denitrification can also play a protective function for nitrogen fixation system, as it has been demonstrated by Garcia-Plazaola et al. (1993) with 13 Rhizobium melilloti strains.
All these potential functions of the denitrification system in symbiotic rhizobia would be especially advantageous in construction of symbiotic associations capable of surviving under frequently occurring anaerobiosis in the soil, which takes place e.g., on areas highly polluted with phenolic compounds. Lupin, which posses a highly developed root system, could play a considerable role in recultivation of such lands. Construction of a symbiotic association between a legume plant and a bacterial strain with an efficient denitrification system could contribute to more effective recultivation of contaminated soils (Vance, 1998).

\section{R E F E R E N C E S}

Alcantar-Gonzales GM, Migianac-Maslow A, Champigny ML. (1988) Effect of nitrate supply on energy balance and acetylene reduction and nitrate reductase activities of soybean root nodules infected with Bradyrhizobium japonicum. CR Acad Sci Paris.; 307: 145-52.

Alikulow ZA, Burichanow Sz, S, Sergiejew NS, Lwow NP, Kretowicz WL. (1980) Nitratreduktaza bakteroidow kłubienkow lupina. Prikładnaja Biochimija Mikrobiotogija.; 16: 511-6.

Appleby CA. (1984) Leghemoglobin and Rhizobium respiration. Annu Rev Plant Physiol.; 35: 443-78.

Arrese-Igor C, Garcia-Plazaola JI, Hernandez A, Aparicio-Tejo PM. (1990) Effect of low nitrate supply to nodulated lucerne on time course of activities of enzymes involved in inorganic nitrogen metabolism. Physiol Plant.; 80: 185-90.

Arrese-Igor C, Minchin FR, Gordon AJ, Nath AK. (1997) Possible causes of the physiological decline in soybean nitrogen fixation in the presence of nitrate. J Exp Bot.; 48: 905-13.

Becana M, Klucas RV. (1992) Oxidation and reduction of leghemoglobin in root nodules of leguminous plants. Plant Physiol.; 98: 1217-21. 
Becana M, Sprent JI. (1987) Nitrogen fixation and nitrite reduction in the root nodules of legumes. Physiol Plant.; 70: 757-65.

Becana M, Aparicio-Tejo PM, Sánchez-Díaz M. (1985a) Nitrate and nitrite reduction by alfalfa root nodules: accumulation of nitrite in Rhizobium meliloti bacteroids and senescence of nodules. Physiol Plant.; 64: 353-8.

Becana M, Aparicio-Tejo PM, Sánchez-Díaz M. (1985b) Nitrate and nitrite reduction in the plant fraction of alfalfa root nodules. Physiol Plant.; 65: 185-8.

Becana M, Minchin FR, Sprent JI. (1989) Shot-term inhibition of legume $\mathrm{N}_{2}$ fixation by nitrate. I. Nitrate effects on nitrate-reductase activities of bacteroids and nodule cytosol. Planta.; 180, 40-5.

Caba JM, Lluch C, Ligero F. (1995) Distribution of nitrate reductase activity in Vicia faba: effect of nitrate and plant genotype. Physiol Plant.; 93: $667-72$.

Campbell WH. (1999) Nitrate reductase structure, function and regulation: bridging the gap between biochemistry and physiology. Annu Rev Plant Physiol Plant Mol Biol.; 50: 277-303.

Caroll BJ, Hansen AP, McNeil DL, Gresshoff PM. (1987) Effect of oxygen supply on nitrogenase activity of nitrate- and darkstressed soybean (Glycine $\max$ L. Merr.) plants. Aust J Plant Physiol.; 146: 79-87.

Chamber-Perez MA, Serrano A. (1991) C-N balance, nitrate and nitrite reductases in Bradyrhizobium sp. (Lupinus) nodules exposed to nitrate, and the relationships to nitrogenase activities. J Plant Physiol.; 139: 70-5.

Chamber-Perez MA, Camacho-Martinez M, Soriano-Niebla JJ. (1997) Nitrate-reductase activities of Bradyrhizobium sp. in tropical legumes: effects of nitrate on $\mathrm{O}_{2}$ diffusion in nodules and carbon costs of $\mathrm{N}_{2}$ fixation. $J$ Plant Physiol.; 150: 92-6.

Champigny ML, Van Ouy L, Moyse A. (1985) Study of the effect of nitrate on symbiosis between soybean (Glycine $\max$ L. Meer.) and Rhizobium japonicum with and without inducible nitrate reductase. CR Acad Sci Paris; 300: 19-23.
Daniel RM, Limmer AW, Steele KW, Smith IM. (1982) Anaerobic growth, nitrate reduction and denitrification in 46 Rhizobium strains. $J$ Gen Microbiol.; 128: 1811-5.

Diaz del Castillo L, Layzell DB. (1995) Drought stress, permeability to $\mathrm{O}_{2}$ diffusion and the respiratory kinetics of soybean root nodules. Plant Physiol.; 107: 1187-94.

Drevon JJ, Derensard C, Iretki H, Payre H, Roy G, Serraj R. (1995) La salinité abaisse la conductans des nodosités á la diffusion de l'oxygéne. In Facteurs Limitant la Fixation Symbiotique de l'Azote dans le Bassin Méditerranen. Drevon JJ. ed, pp 73-84. INRA (Les Colleques nr 77): Paris.

Garcia-Plazaola JI, Beccerril JM, Arrese-Igor C, Hernandez A, Gonzales-Murua C, AparicioTejo PM. (1993) Denitrifying ability of thirteen Rhizobium meliloti strains. Plant Soil; 149: 43-50.

Giannakis C, Nicholas DJD, Wallace W. (1988) Utilization of nitrate by bacteroids of Bradyrhizobium japonicum in the soybean root nodule. Planta.; 174: 51-8.

Greenwood DJ. (1982) Nitrogen supply and crop yield: the global scene. Plant Soil.; 67: 45-9.

Heckman MO, Drevon JJ. (1987) Nitrate metabolism in soyeban root nodules. Physiol Plant.; 69: $721-5$.

Hunter WJ. (1983) Soybean root and nodule nitrate reductase. Physiol Plant; 59: 471-5.

Ianetta PPM, de Lorenzo C, James EK, Fernandez-Pascual M, Sprent JI, Lucas MM, Witty JF, de Felipe MR, Minchin FR. (1993) Oxygen diffusion in lupin nodules. I. Visualisation of diffusion barrier operation. J Exp Bot.; 44: $1461-7$.

Ismade J. (1991) Regulation of the nodule efficiency by the undisturbed soybean plant. $J$ Exp Bot.; 42: 687-91.

James EK, Sprent JI, Minchin FR, Brewin NJ. (1991) Intracellular location of glycoprotein in soybean nodules: effect of altered rhizosphere oxygen concentration. Plant Cell Environ.; 14: 467- 76 . 
Kaiser WM, Huber SC. (2001) Post-translational regulation of nitrate reductase: mechanism, physiological relevance and environmental triggers. J Exp Bot.; 52: 1981-9.

Kuzma MM, Topunow AF, Layzell DB. (1995) Effects of temperature on infected cell $\mathrm{O}_{2}$ concentration and adenylate levels in attached soybean nodules. Plant Physiol.; 107: 1103-13.

Lang P, Martin R, Golvano MP. (1993) Effect of nitrate on carbon metabolism and nitrogen fixation in root nodules of Lupinus albus. Plant Physiol Biochem.; 31: 639-48.

Layzell DB, Hunt S. (1990) Oxygen and the regulation of nitrogen fixation in legume nodules. Physiol Plant.; 80: 322-7.

Layzell DB, Hunt S, Palmer GR. (1990) Mechanism of nitrogenase inhibition in soybean nodules: pulse-modulated spectroscopy indicates that nitrogenase activity is limited by $\mathrm{O}_{2}$. Plant Physiol.; 92: 1101-7.

Malik NSA. (1983) Grafting experiments on the nature of the decline in $\mathrm{N}_{2}$ fixation during fruit development in soybean. Physiol Plant.; 57: $561-4$.

Manhart JR, Wong PP. (1980) Nitrate effect on nitrogen fixation (acetylene reduction) activities of legume root nodules induced by rhizobia with varied nitrate reductase activities. Plant Physiol.; 65: 502-5.

Minchin FR. (1997) Regulation of oxygen diffusion in legume nodules. Soil Biol Biochem.; 29: 881-8.

Minchin FR, Minquez MI, Sheehy JE, Witty JF, Skot L. (1986a) Relationships between nitrate and oxygen supply in symbiotic nitrogen fixation by white clover. J Exp Bot.; 37: 1103-113.

Minchin FR, Sheehy JE, Witty JF. (1986b) Further errors in acetylene reduction assay: Effects of plant disturbance. $J$ Exp Bot.; 37: 1581-91.

Minchin FR, Becana M, Sprent JI. (1989) Short-term inhibition of legume $\mathrm{N}_{2}$ fixation by nitrate. II. Nitrate effect on nodule oxygen diffusion. Planta.; 180: 46-52.

Noel KD, Carneol M, Brill WJ. (1982) Nodule protein synthesis and nitrogenase activity of soy- beans exposed to fix nitrogen. Plant Physiol.; 70: $1236-41$

O’Hara GW, Daniel RM (1985) Rhizobial denitrification: A review. Soil Biol Biochem.; 17: 1-9.

Parsons R, Day DA. (1990) Mechanisms of soybean nodule adaptation to different oxygen pressures. Plant Cell Environ.; 13: 501-12.

Parsons R, Stanforth A, Raven JA, Sprent JI. (1993) Nodule growth and activity may be regulated by a feedback mechanism involving phloem nitrogen. Plant Cell Environ.; 16: 125-36.

Polcyn W, Luciński R. (2001) Functional similarities of nitrate reductase from yellow lupine bacteroids to bacterial denitrification system. J Plant Physiol.; 158: 829-34.

Randall DD, Russell WJ, Johnson DR. (1978) Nodule nitrate reductase as a source of nitrogen in soybean, Glicyne $\max (\mathrm{L})$. Physiol Plant.; 44: 325-8.

Ratajczak L, Ratajczak W, Mazurowa H, Woźny A. (1996) Respiratory activity of bacteroids and mitochondria in root nodules of yellow lupine. Biol Bull Poznań.; 33: 35-40.

Riguard J. (1976) Effect des nitrates sur la fixation d'azote per les nodules de Haricot (Phaseolus vulgaris L.). Physiol Veg.; 14: 297-308.

Robertson JG, Wells B, Bisseling T, Farnden KJF, Johnston AWB. (1984) Immuno-gold localization of leghemoglobin in cytoplasm in nitrogen-fixing root nodules of pea. Nature.; 311: 254-6.

Schuller KA, Minchin FR, Gresshoff PM. (1988) Nitrogenase activity and oxygen diffusion in nodules of soybean cv. Bragg and a supernodulating mutant: effect of nitrate. $J$ Exp Bot.; 39: 865-77.

Serraj R, Drevon JJ, Obaton M, Vidal A. (1992) Variation in nitrate tolerance of nitrogen fixation in soybean (Glicyne max) - Bradyrhizobium symbiosis. J Plant Physiol.; 140: 366-71.

Serraj R, Sinclair TR, Purcell LC. (1999) Symbiotic $\mathrm{N}_{2}$ fixation response to drought. $J$ Exp Bot.; 50: 143-55.

Serrano A, Chamber M. (1990) Nitrate reduction in Bradyrhizobium sp (Lupinus) strains and its 
effects on their symbiosis with Lupinus luteus. J Plant Physiol.; 136: 240-6.

Small JGC, Leonard OA. (1969) Translocation of ${ }^{14} \mathrm{C}$-labelled photosynthetates in nodulated legumes as influenced by nitrate nitrogen. Amer J Bot.; 56: 187-94.

Solomonson LP, Barber MJ. (1990) Assimilatory nitrate reductase: Functional properties and regulation. Annu Rev Plant Physiol Plant Mol Biol.; 41: 225-53.

Sprent JI, Giannakis C, Wallace W. (1987) Transport of nitrate and calcium into legume root nodules. J Exp Bot.; 38: 1121-8.

Streeter JG. (1988) Inhibition of legume nodule formation and $\mathrm{N}_{2}$ fixation by nitrate. CRC Crit Rev in Plant Sci.; 7: 1-23.

Streeter JG. (1994) In Plant-Environment Interactions Symbiotic Nitrogen Fixation. Wilkinson RE. ed, pp. 245-62. Marcel Dekker Inc, New York-Basel-Hong Kong.

Unden G. (1997) Alternative respiratory pathways of $E$ coli: energetics and transcriptional regulation in response to electron acceptors. Biochem Biophys Acta.; 1320: 217-34.

Vance CP. (1990) Symbiotic nitrogen fixation: recent genetic advances. In The Biochemistry of Plants: Intermediary Nitrogen Metabolism. Miflin BJ, Lea PJ. eds, vol 16, pp 48-88. Academic Press, San Diego.

Vance CP. (1998) Legume symbiotic nitrogen fixation: argonomic aspects. In The Rhizobiace: Molecular Biology of Model Plant-Associated Bacteria. Spaink HP, Kondorosi A, Hooykas
JJ. eds, pp 509-30. Kluvier Academic Publishers.

Vessey JK, Waterer J. (1992) In search of the mechanism of nitrate inhibition of nitrogenase activity in legume nodules: recent developments. Physiol Plant.; 84: 171-6.

Vessey JK, Walsh KB, Layzell DB. (1988a) Oxygen limitation of $\mathrm{N}_{2}$ fixation in stem-girdled and nitrate-treated soybean. Physiol Plant.; 73: 113-21.

Vessey JK, Walsh KB, Layzell DB. (1988b) Can a limitation in phloem supply to nodules account for the inhibitory effect of nitrate on nitrogenase activity in soybean? Physiol Plant.; 74: 137-46.

Waisel Y, Eschel A, Kafkafi U. (1998) Legume symbiotic nitrogen fixation: argonomic aspects. In The Rhizobiace: Molecular Biology of Model Plant-Associated Bacteria. Spaink HP, Kondorosi A, Hooykas JJ. eds, pp 525-6. Kluwer Academic Publishers.

Walsh KB, McCully ME, Canny MJ. (1989) Vascular transport and soybean nodule function: Nodule xylem is a blind alley, not a throughway. Plant Cell Environ.; 12: 395-405.

Witty JF, Minchin FR, Sheehy JE, Minguez MI. (1984) Acetylene induced changes in the oxygen diffusion resistance and nitrogenase activity of legume root nodules. Ann Bot.; 53: 13-20.

Witty JF, Minchin FR, Skot L, Sheehy JE. (1986) Nitrogen fixation and oxygen in legume root nodules. Oxfort Surveys Plant Molec Cell Biol.; 3: $275-314$. 